\title{
Biocontrol Properties and Functional Characterization of Rice Rhizobacterium Pseudomonas sp. VSMKU4036
}

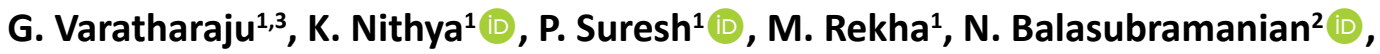 \\ S. Gomathinayagam ${ }^{4}$, P.T. Manoharan ${ }^{3}$ and V. Shanmugaiah ${ }^{1 *}$
}

\begin{abstract}
${ }^{1}$ Department of Microbial Technology, School of Biological Sciences, Madurai Kamaraj University, Madurai - 625 021, Tamil Nadu, India. ${ }^{2}$ Department of Immunology, School of Biological Sciences, Madurai Kamaraj University, Madurai - 625 021, Tamil Nadu, India. ${ }^{3}$ Department of Botany, Vivekananda College, Thiruvedagam (West), Madurai - 625 214, Tamil Nadu, India. ${ }^{4}$ Faculty of Agriculture and Forestry, University of Guyana, Berbice Campus, Tain, Guyana, South America.
\end{abstract}

\begin{abstract}
A total of 30 fluorescent pseudomonads (FPs) were showed significant antagonistic activity against different fungal phytopathogens with different level of the zone of inhibition (ZOI) for Rhizoctonia solani $(5 \mathrm{~mm}-34 \mathrm{~mm})$, Macrophomina phaseolina $(9 \mathrm{~mm}-37 \mathrm{~mm})$, Scleotium rolfsii $(4 \mathrm{~mm}-36 \mathrm{~mm})$, Helminthusporium solani $(5 \mathrm{~mm}-27 \mathrm{~mm})$, Fusarium oxysporum $(2 \mathrm{~mm}-25 \mathrm{~mm})$ and Fusarium oxysporum RACE $(4 \mathrm{~mm}-31 \mathrm{~mm})$ compared to control. The maximum growth of our selected isolate VSMKU4036 was observed in King'B Broth (KBB), pH 7.0 and at $37^{\circ} \mathrm{C}$. The VSMKU4036 isolate has been recognized as Pseudomonas sp, based on the morphological, biological, and different functional characteristics. Antagonistic rhizobacterium Pseudomonas sp VSMKU4036 produced antimicrobial traits, such as plant growth promotion and various functional characters like siderophores, hydrogen cyanide (HCN), phosphate solubilization, indole acetic acid (IAA), biofilms formation, protease, gelatinase, amylase, and pectinase. Our superior biocontrol isolate VSMKU4036 was high resistance to tetracycline, streptomycin and nalidixic acid, however, it was sensitive to ampicillin and rifamycin. Pseudomonas sp VSMKU4036 showed maximum resistance to cadmium, nickel chloride, copper sulphate, magnesium sulphate, zinc chloride and ferric chloride where as highly sensitive to mercuric chloride, and selenium dioxide compared to control.
\end{abstract}

Kewwords: Pseudomonas sp, biocontrol, functional characters, resistance, sensitivity

\footnotetext{
*Correspondence: shanmugaiahv@gmail.com

(Received: April 09, 2020; accepted: June 17, 2020)

Citation: Varatharaju G, Nithya K, Suresh P, et al. Biocontrol Properties and Functional Characterization of Rice Rhizobacterium Pseudomonas sp. Vsmku4036. J Pure Appl Microbiol. 2020;14(2):1545-1556. doi: 10.22207/JPAM.14.2.53

(C) The Author(s) 2020. Open Access. This article is distributed under the terms of the Creative Commons Attribution 4.0 International License which permits unrestricted use, sharing, distribution, and reproduction in any medium, provided you give appropriate credit to the original author(s) and the source, provide a link to the Creative Commons license, and indicate if changes were made.
} 


\section{INTRODUCTION}

In recent scenario, the tremendous increase of population and industries are given a huge task to the environment and agriculture sectors by the way terrestrial and agricultural land has been polluted by industrial and human waste. Due to the accumulation of toxic heavy metals and continuous application of antibiotic residues have drastically inhibited the growth of the microbial population. Besides, about $90 \%$ of microbial beneficial character would be declined due to toxic heavy metals and chemical fertilizer deposits. Moreover, the soil is an ordinary source for all the plants, animals, and microorganisms because they depend on soil directly or indirectly for their survival. Rhizobacteria are responsible for promoting plant growth and protecting plants from various natural and artificial proceedings and also for the nutrient cycling in the soil (Liu et al., 2013).The intense use of chemical fertilizers and pesticides is causing significant threats to the atmosphere and to community health (Riah et al., 2014). The continuous usage of these chemicals' fertilizers discharged the heavy metals through irrigation for a long duration in the agricultural field, suppose if keep on doing this practice in the field of agriculture, the soils will become impotent. Further, through this practice non-biodegradable materials enter into our food chain. Hence, most of the agriculturally important crops were attained the risk of all life forms (Lal et al., 2013).

The development of threshold chemicals is affecting microbial diversity and reduce soil fertility. It will create a negative impact on human health (Huang et al., 2009). Numerous Industries together with electroplating, chemical manufacturing, paper making, printing and dyeing, hardware and leather industries discharge their untreated effluents along with different heavy metals toward soil and water bodies. Hence, an alternative measure is urgently needed for reducing heavy metals. The use of bioherbicides, biopesticides, bioinsecticides, and bio fungicides, etc., is the alternative to the agrochemicals for the protection of the environment, plants and all kinds of herbivorous animals and rhizosphere microbes from the health defects. Therefore, promoting, this practice must be prime research to identify the potential biocontrol agents (Baishya and Sarma, 2014).
The rhizosphere directly influences the microbial substance with interrelationship to promote the richness of the population (Kloepper et al., 1999; Antoun and Kloepper, 2001). Freeliving rhizobacteria are associated with the rhizospheric region to form symbiotic relationships with plants, the plant secrets specific organic compounds that are used for competition for nutrients and solid attachment sites, this type of mechanism unlighted to determine the symbiotic relationships (Singh et al., 2013).

Microorganisms are adapting themselves when they are exposed to polluted environments at different absorptions of heavy metals then microbes will become highly resistant to metals. Among different trace metals, an inorganic fertilizer phosphate becomes a major natural resource (Lu et al., 1992; Saberi and Hassan, 2014). Since, most of the antagonistic bacteria are solubilizing Phosphate, through which, microbes were stimulating the plant development. Naturally, soil-borne bacteria obtained, the potential for produce growth hormones, siderophores, antibiotics, symbiotic $\mathrm{N}_{2}$ fixation, hydrolytic enzyme production, and other nutrients secretion for protection of plants from pathogenic microbes (Bharathi et al., 2004; Ahmad et al., 2006; Egamberdiyeva, 2007). Due to biocontrol and growth-promoting capacity for control of pathogens with diverse mechanisms (Shanmugaiah et al., 2010), fluorescent pseudomonades (FPs) have been attracting much attention worldwide in recent days.

Almost all species of pseudomonades can produce a growth substance like auxin, cytokinins, siderophore, Hydrogen Cyanide ( $\mathrm{HCN}$ ), production of antibiotics against multiple drug-resistant bacteria (MDR), antifungal and antibacterial effect of plant pathogens (Alstrom and Burns, 1989; Bauer et al., 1996; Glick et al., 1998; Lata, 2003). An antagonistic potential of toxic mineral resistant rhizobacterium is most important for plant health. Hence, this present research work focused with different objectives (i) Antagonistic activity of FPs towards different diseases causing soil-borne fungus (ii) screening for functional characters such as siderophore, HCN, IAA, biofilm, phosphate solubilization and hydrolytic enzyme production (iii) to evaluate the selected isolate VSMKU3046 
for resistance and sensitivity to various heavy metals and different antibiotics.

\section{MATERIALS AND METHODS \\ Fluorescent pseudomonad's (FPs)}

A total of $30 \mathrm{FPs}$ was isolated from rice rhizosphere, Southern districts of Tamil Nadu, India. All FPs were preserved in King's B agar medium (King et al., 1954) and 30\% glycerol stock at $80^{\circ} \mathrm{C}$ for further research work.

\section{Fungal pathogens}

The phyto pathogens were obtained from our laboratory collection and that have been maintained in a particular medium with a controlled environment. Further fungal strains in a specialized setting with the specific medium and maintenance were elaborately stated in our previous report (Nithya et al., 2019).

FPs against plant fungal pathogens

FPs were tested towards soil borne disease causing pathogens such as $R$. solani, $S$. rolfsii, M. phaseolina, H. solani, F. oxysporum and F. oxysporum RACE by dual plate method with three replications (Shanmugaiah et al., 2010). One-day old FPs grown on King's B agar was streaked at the edge of the Petri plate, $3 \mathrm{~cm}$ from the mycelial disk, and the disks were kept for three days at $28 \pm 2^{\circ} \mathrm{C}$. Based on the superior antagonistic potential activity isolate VSMKU4036 was selected for additional studies.

Biochemical analysis for selected isolate VSMKU4036

The isolate VSMKU4036 was defined based on the features of morphological character, color development, and cluster appearances. Best owing to Bergey's Manual of Determinative Bacteriology (Williams et al., 1994), most of the biochemical tests were performed.

Growth of Pseudomonas sp VSMKU4036 in different media

The isolate VSMKU4036 was grown up in three nutrient solutions like King's B broth (KBB), Nutrient broth (NB) and Luria Bertani broth (LBB) was used to govern the best growth and cultural circumstances for the supreme growth. Approximately $100 \mathrm{ml}$ of separate medium was fitted with a conical decanter in $250 \mathrm{ml}$, after sterilization $1 \mathrm{ml}$ of preculture (Pseudomonas sp VSMKU4036) was inoculated in each flask. Culture was introduced separately in each medium and that was kept on in environmental shaker at $28 \pm 2^{\circ} \mathrm{C}$ for $200 \mathrm{rpm}$ up to $24 \mathrm{hrs}$. We quantified growth at $600 \mathrm{~nm}$ by spectrophotometer.

Growth of VSMKU4036 at various pH and temperature

Pseudomonas sp VSMKU4036 progress was optimized at various temperatures $\left(25^{\circ} \mathrm{C}\right.$ to $45^{\circ} \mathrm{C}$ ) and $\mathrm{pH}(3-10)$. The growth of the isolate VSMKU4036 was raised in an environmental shaker at $200 \mathrm{rpm}$ and the OD was read at 600 $\mathrm{nm}$ (Shanmugaiah et al., 2010). The growth was measured in King' B broth up to 24 hrs compared to control.

\section{Qualitative assay for IAA}

Pseudomonas sp VSMKU4036 was grown in King's B broth, added with $0.1 \mathrm{mg} / \mathrm{ml}$ of Tryptophan in $250 \mathrm{ml}$ conical flask and incubated up to $48 \mathrm{hrs}$ at $28 \pm 2^{\circ} \mathrm{C}$. The bacterial culture was collected by centrifugation at $10,000 \mathrm{rpm}$ for 10 min. Cells free culture filtrate was assorted with 2 $\mathrm{ml}$ of Salkowski's combination ( $2 \% 0.5 \mathrm{FeCl} 3$ in $35 \%$ HCLO4 solution) and incubate in a shady condition for about $30 \mathrm{~min}$. The establishment of pink color specifies the creation of IAA.

\section{Siderophore Production}

Iron chelating agent siderophore creation by VSMKU 4036 was observed by the technique of Schwyn and Neilands (1987). Biocontrol isolate VSMKU4036 was developed for 48 hrs in King's B medium (King et al., 1954). King's B medium inoculated with 2 mol I- 1 pasteurized filter FeSO4$7 \mathrm{H}_{2} \mathrm{O}$ was used as a control aid. The culture was centrifuged for $10 \mathrm{~min}$ at $10,000 \mathrm{rpm}$, and $1 \mathrm{ml}$ of cell-free suspension was combined with $1 \mathrm{ml}$ of chrome-azurol S solution (Himedia, India). After $15 \mathrm{~min}$, the medium color switched from blue to reddish-brown. Reddish-brown color development was indicated the production of siderophores by our selected isolate Pseudomonas sp VSMKU4036. Production of Hydrogen cyanide (HCN)

The Lorck method (1948) estimated the output of HCN by VSMKU4036 isolate.

Qualitative assay for Phosphate solubilization and Hydrolytic enzymes

Our fresh culture Pseudomonas spVSMKU4036 was spotted on the medium Pikovskaya (Pikovskaya, 1948) (pH 6.8) and hatched up to 2 days at $28^{\circ} \mathrm{C}$. The clear zone was 
observed around selected isolate VSMKU4036. The production of hydrolytic enzymes like chitinase, cellulase, gelatinase, protease, amylase and pectinase by our isolate VSMKU4036 in a nutrient agar medium, added with $1 \%$ individual substrates. Assay for Biofilm formation by Pseudomonas sp. VSMKU4036

The selected isolate Pseudomonas sp. VSMKU4036 was inoculated in a glass tube containing King's B nutrient solution hatched at $37^{\circ} \mathrm{C}$ in static condition up to two days. Pseudomonas fluorescence PF5 and Pseudomonas fluorescence $\mathrm{CHAO}$ were used as a positive control. After the incubation period, the culture was drained from the culture tube. The culture tubes were washed thoroughly with sterilized distilled water, followed by $1 \%$ of crystal violet solution was added to the attached cells in test tubes, and kept for 10 to $15 \mathrm{~min}$ at room temperature (Merritt et al., 2011). The culture tubes were rinsed with distilled water again to remove unwanted traces and the biomass of attached cells (biofilm) was quantified by solubilization of dye in $5 \mathrm{ml}$ of $95 \%$ ethanol (Konstanze et al., 2019). The absorbance was measured at $600 \mathrm{~nm}$.

\section{Heavy metal resistance/sensitivity test of VSMKU4036}

The resistance/sensitivity of isolated VSMKU4036 was tested with commercially available heavy metals like Lead acetate, Cadmium sulphate, Nickel cholride, Selenium dioxide, Zinc chloride, Ferric chloride, Copper sulphate, Mercuric chloride and Magnesium sulphate with different concentrations by well diffusion method. The $24 \mathrm{~h}$ old culture of VSMKU4036 was swabbed on the nutrient agar (NA) and completely allowed to dry up to $10 \mathrm{~min}$ before making the wells. About $9 \mathrm{~mm}$ wells were made in NA by the sterile cork borer. After that, the above mentioned heavy metals with various concentrations $(1,2,4,6,8$ and $10 \mathrm{mM} / \mathrm{ml}$ ) was introduced into the wells. The plates were hatched $24 \mathrm{hrs}$ at $30^{\circ} \mathrm{C}$ up to bacterial development was noticed. The diameter $(\mathrm{mm})$ of each zone was measured and recorded at the end of the incubation. The outlines of sensitivity and resistance were verified based on the diameter of the inhibitory zone and the test was carried out providing the standard map.

\section{Antibiotic resistance/sensitivity test of VSMKU4036}

Antibiotic resistance/sensitivity test for the isolate VSMKU4036 was performed with commercially available antibiotics such as tetracycline, ampicillin, rifampicin, streptomycin and nalidixic acid with different concentrations by the well diffusion method. The $24 \mathrm{hrs}$ old culture VSMKU4036 was swabbed on the nutrient agar (NA) and completely allowed the surface to dry for 10 min before making the well in NA. About $9 \mathrm{~mm}$ wells were made in NA by the sterile cork borer. After that, the above-mentioned antibiotics with different concentration $(25,50,75$ and 100 $\mu \mathrm{g} / \mathrm{ml}$ ) were added into the wells. The plates were hatched upto $24 \mathrm{hrs}$ at $30^{\circ} \mathrm{C}$ till bacterial growth was detected. The diameter $(\mathrm{mm})$ of each zone was measured and noted at the end of gestation. The sensitivity and resistance profiles were verified based on the diameter of the clearance of the zone and the assessment according to the standard chart.

\section{RESULTS AND DISCUSSION \\ Antifungal activity of isolate VSMKU4036}

Among $30 \mathrm{FPs}, 27$ isolates of FPs were shown the different spectrum of biocontrol activity towards various fungal plant pathogens. Of which an isolate was showed superior antagonistic activity against various fungal phytopathogens designated as VSMKU4036. The minimum antagonistic activity was observed against $R$. solani. However, the prominent antagonistic activity was observed against $M$. phaseolina from $9 \mathrm{~mm}$ to $38 \mathrm{~mm}$ compared to control (Table 1). Fluorescent pseudomonades are predominantly obtained from the various rhizosphere such as rice, sugarcane, groundnut and banana (Charulatha et al, 2013). Beneficial microbes like Pseudomonas spp, Bacillus spp, Streptomyces sp and Tichoderma spp are continuously giving strong antagonistic potential, further antagonistic microbe would be developed as a bio-inoculant for plant growth and plant protection (Shanmugaiah et al., 2008; Shanmugaiah et al., 2015; Harikrishnan et al., 2016; Vaishnavi et al., 2019). Among different PGPR, fluorescent pseudomonads are significant groups of microbes in agricultural crop protection. 
Table 1. Antagonistic activity of Pseudomonas sp. against plant fungal pathogens

\begin{tabular}{llcc}
\hline No. & Plant pathogenic fungus & $\begin{array}{c}\text { No. of } \\
\text { FPs isolates }\end{array}$ & $\begin{array}{c}\text { Zone of } \\
\text { Inhibition }(\mathrm{mm})\end{array}$ \\
\hline 1 & Rhizoctonia solani & 17 & $5-34$ \\
2 & Macrophomina phaseolina & 23 & $9-38$ \\
3 & Sclerotium rolfsii & 22 & $4-36$ \\
4 & Helminthusporium solani & 20 & $3-27$ \\
5 & Fusarium oxysporum & 27 & $2-25$ \\
6 & Fusarium oxysporum RACE & 24 & $4-31$ \\
\hline
\end{tabular}

Hence, the efficacy of FPs for the promotion of plant growth and the scope for biocontrol established by various researchers (Shanmugaiah et al., 2006; Zhou et al., 2012; Mohammed et al., 2020).

\section{Identification of selected isolate VSMKU4036}

Selected isolate VSMKU4036 is gram's negative, motile, rod shape, catalase oxidasepositive and optimum temperature is $37^{\circ} \mathrm{C}$. Further, based on the morphology, fluorescent pigment production, physiological and various biochemical analyses, the selected isolate was identified as Pseudomonas sp (Table 2).

FPs can produce pyocyanin pigments, which indicates, the production of phenazine. Phenazine pigments contain reactive nitrogen intermediate (RNI), RNI is important for antimicrobial activity. Hence, the presence of pyocyanine pigments indicates the selected isolate

Table 2. Biochemical analysis of Pseudomonas sp VSMKU4036

Morphology, biochemical
and functional characters

\begin{tabular}{lc}
\hline Gram's staining & - \\
Shape & Rod \\
Catalase & + \\
Oxidase & + \\
Blood Agar growth & - \\
Indole & - \\
Glucose & + \\
Mannitol & + \\
Methyl Red & - \\
VogesProskeur & - \\
SimmonCitrate Agar & + \\
Temperature & $37^{\circ} \mathrm{C}$
\end{tabular}

comes under the genus Pseudomonas. Some of the biochemical assays facilitate for identification of Pseudomonas spp up to the genus level, such as catalase, oxidase, citrate utilization, and mannitol reactions are positive compared to control (Charulatha et al., 2013).

\section{Optimum growth of VSMKU4036}

The maximum growth of selected isolate Pseudomonas sp VSMKU4036 was observed in King's B Broth with a pH 7.0 at $37^{\circ} \mathrm{C}$ compared to other media, $\mathrm{pH}$, temperature, and control (Fig. 1, $2 \& 3)$.

Numerous biotic and abiotic factors play a significant role in the development of microorganism both in lab and field conditions. For example, aeration is needed for aerobic bacterial and become a restrictive influence for the progress of Pseudomonas sp. The unexpected shape of the growth curve would be developed due to the depletion of oxygen and changes in metabolism. Most of the microbial growth, nitrate as an alternate electron acceptor and can grow an aerobically (Palleroni, 1991). Further, different carbon, nitrogen, and metals sources could be enhanced the production of microbial substances or products (Shanmugaiah et al., 2008).

\section{Biocontrol mechanism by Pseudomonas sp VSMKU4036}

Numerous biocontrol principles like Antibiosis, parasitism, induced resistance, and nutrient competition were identified as diverse mechanisms for biological control of various plant diseases (Harikrishnan et al., 2016). The remarkable bio-inoculants are giving good results under controlled conditions (Timmusk et al., 2017). Basic understanding of molecular action that leads to the advancement of bio-regulation of 
biological control agents (BCAs) is very important for the application of an actual antagonistic effect in agrarian fields.

In this present study, we selected isolate VSMKU4036 was produced hydrolytic enzymes like protease, amylase, gelatinase, and pectinase, however, the isolate VSMKU4036 did not produce chitinase and cellulase (Table 3 ). Hydrolytic enzymes like protease, gelatinase, amylase, pectinase, chitinase and cellulase play an important role in altering the cell walls of fungi. Because, these enzyme, which could be involved in the control of different plant diseases like Verticillium wilt of cotton, common blight of bean and rice diseases (Yang et al., 2008; Shanmugaiah et al., 2008; Zheng et al., 2011). Further, glucanase, siderophores, hydrogen cyanide, and volatile substance production showed the direct antagonistic consequence and for the nutrition competition, by the way, FPs are effectively controlling the sheath blight of rice and Ralstonia wilt of ginger (Shanmugaiah et al., 2010; Yang et al., 2012).

Our isolate VSMKU4036 produced various biocontrol traits like solubilization of phosphate, IAA, iron-chelating agents siderophore, $\mathrm{HCN}$, and

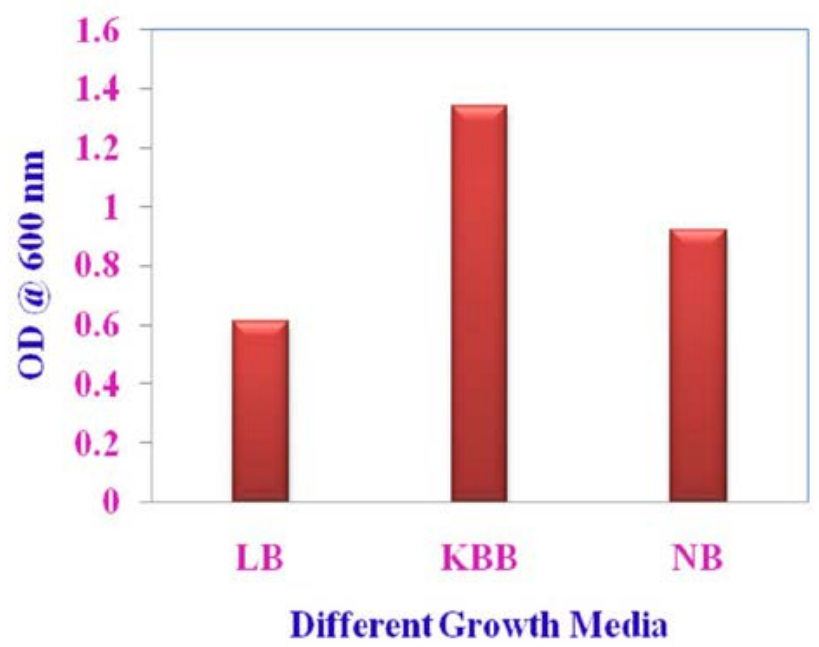

LB: Luria Bertani Broth, KBB: King's B Broth, NB: Nutrient Broth

Fig. 1. Growth of Pseudomonas sp VSMKU4036 at different medium

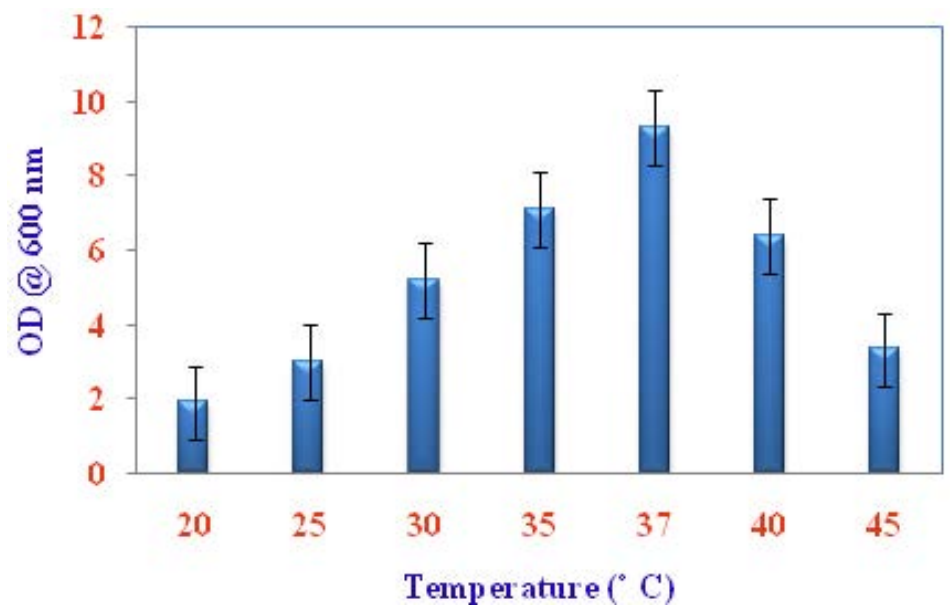

Fig. 2. Growth of Pseudomonas VSMKU4036 at various temperatures 
biofilm formation compared to control (Table $3)$. Phosphate $(P)$ solubilization is one of the most essential elements for plants survival and it is understood that P-solubilizing microbes are increasing inorganic phosphate by allowing the mineralization of impenetrable phosphate content to a soluble state via excreting organic acids by antagonistic FPs (Gyaneshwar et al., 2002; Buch et al., 2008). FPs can produce up to $50 \%$ of the total rhizosphere microbial inhabitants and other soil microbes solubilize phospahte (Sharma et al., 2013).

The prime plant regulating substances such as IAA, phytohormones are stimulating and increasing plant biomass. Rhizobacteria (PGPR) is producing plant growth substances for the development of root and stem system (Vacheron et al., 2013). Similarly, FPs are concealing ironstrarvation substance molecules to boost the Fe nutrition status in the field of agricultural sector (Ahemad and Kibret, 2014). Iron healing agents are recognized and produced immune system for the suppression of bacterial and fungal pathogens by the competition of iron attainment (Aznar and Dellagi, 2015). The volatile molecules are produced by plant obtained rhizobacterium, especially FPs against various plant pathogens. Various rhizosphere isolates are known to produce cyanogenic toxic effects on different prokaryotic as well as eukaryotic pathogens (Cernava et al., 2015). Bofilm layers are formed in all parts of plants (stems, leaves, plant rhizosphere, soil particles and organic compost) by rhizobacterial community producing exopolysaccharides (Prigent-Combaret et al., 2012).

In recent days research has been explored that antagonistic bacteria could form a bio-plastic layer and adhesion on most of the plants as well as rhizosphere. Due to the formation of biofilm by rhizobacteria more antimicrobial substance could be encouraged by sugar substance are called root exudates (Zhang et al., 2015; Zhou et al., 2016). The previous studies concentrated on the mechanisms of biocontrol and were linked to the possessions of the developed biofilm by antimicrobial material excretion.

\section{Antibiotic resistance/sensitivity}

Among five commercially available antibiotics, our isolate VSMKU4036 was high resistance to tetracycline, moderate resistance to streptomycin and nalidixic acid, however less resistant to ampicillin. Despite this, our isolate is highly sensitive to rifampicin compared to control (Table 4). According to our literature survey, Pseudomonas stutzeri ST6 found several resistant to heavy metals and antibiotics (Barbieri et al., 1989).

In agreement with our result, the majority of the bacteria are highly resistant to antibiotics, because of the rigorous usage of antibiotics together with agriculture and medicine (Levy, 1998). Moreover, in the Indian ecosystem predominantly antibiotic-resistant microbes were present in the agriculture and water bodies (Malik et al., 2008; Ansari et al., 2008). Based on the resistance and sensitivity, we could find out the stability and viability of antagonistic microbes in the rhizosphere of different agriculture crops. In general, the antibiotic resistance genes were transferred through transconjugation, since plasmids are ubiquitous in Pseudomonas spp. As per our observation, an exploration of the viability of antagonistic microorganisms in the agriculture filed was confirmed through the transmission of conjugative plasmids or gene disperses by horizontal transfer. It is also one of the key reasons why multiple antibiotic resistances evolve (Malik and Aleem, 2011). But, in addition, antibiotic development of microorganisms associated with the rhizosphere is widely accepted for growth-promotion and biocontrol capacity against pathogenic microbes (Glick et al., 2007; Shanmugaiah et al., 2010).

\section{Heavy metal resistance/sensitivity}

Our selected isolate Pseudomonas sp VSMKU4036 exhibited a different range of resistance and sensitivity towards heavy metals. Among nine different heavy metals, our isolate was maximum resistance to cadmium sulfate, magnesium sulfate, copper sulfate, zinc sulfate, ferric chloride, and nickel chloride and less resistance to selenium dioxide. In comparison, the extreme sensitivity to acetate and mercury chloride as compared to control was observed (Table 5).

The earlier study was stated that, similar to our results most of the bacterial isolates showed high resistance to zinc and iron associated to 


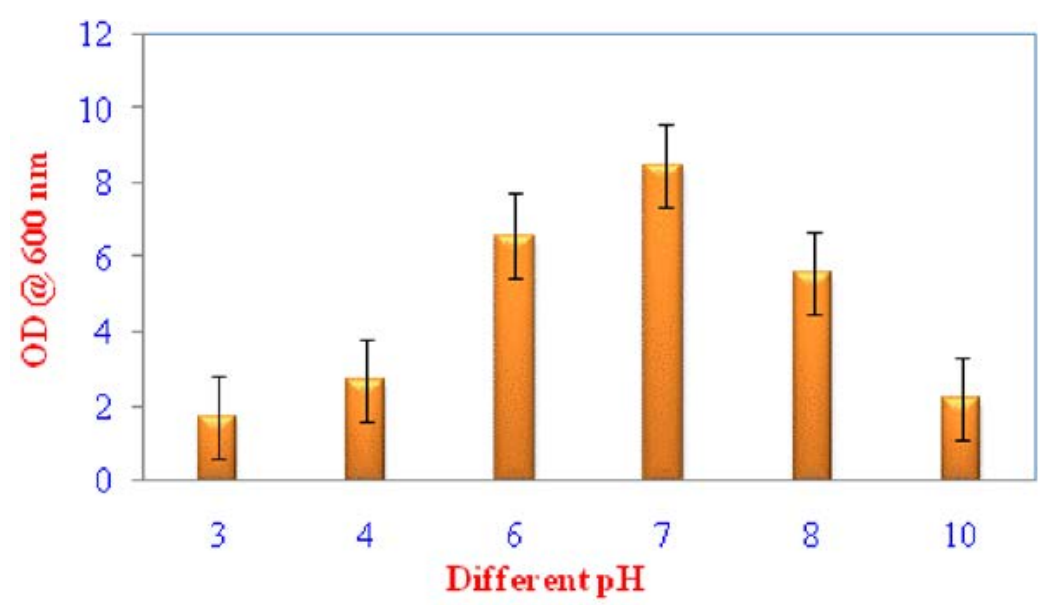

Fig. 3. Growth of Pseudomonas VSMKU4036 at different pH

lead, In another way, some of the heavy metal like mercury and cadmium were the most toxic, thereby inhibiting the growth of rhizobacterial isolates even in lower concentration compared to control, because, if the concentration of heavy metals increase, the metal become representing a toxic effect on the development of rhizobacterial isolates (Mohan et al., 2016).

Continuous deposition of $\mathrm{Cd}$ in agriculture has resulted in various physiological, biochemical and plant absorption of mineral nutrients. In another way, cd accumulation could be disrupted the Calvin cycle and photosynthesis biochemical reactions (Mobin and Khan 2007). Since, the fluctuations in biochemical reaction in most of the

Table 3. Functional characters of Pseudomonas sp VSMKU4036

\begin{tabular}{lc}
$\begin{array}{l}\text { Functional } \\
\text { characters }\end{array}$ & $\begin{array}{c}\text { Positive }(+) / \\
\text { Negative }(-)\end{array}$ \\
\hline Protease & + \\
Amylase & + \\
Gelatinase & + \\
Pectinase & + \\
Cellulase & - \\
Chitinase & - \\
Phosphate & + \\
solubilization & + \\
IAA & + \\
Siderophore & + \\
HCN & + \\
Biofilm formation & + \\
\hline
\end{tabular}

plants, finally, the production level going to be very less compared to less heavy metal amended soils (Feng et al., 2010). Most of the previous studies showed that heavy metal resistance is expressed regularly by plasmid and transposon-positioned genes and is also transferable in situ microflora to native microflora (Malik and Jaiswal, 2000). Cadmium is not intricate in any helpful biotic processes, and it is recognized to disturb enzyme activities, impede DNA-mediated transformation in microorganisms. Further, this toxic metal is interfering with the symbiosis between microbes and plants, and increase plant disposition to attack of plant, fungal pathogens (Kabata-Pendias and Pendias, 2001).

Even, after a small yield of heavy metals such as Sd, Cd, and Mc was consumed by human and animals which enter into the food chain

Table 4. Evaluation of Antibiotic Resistance of Pseudomonas sp. VSMKU4036

\begin{tabular}{llllll}
\hline \multirow{2}{*}{ No. } & Name of & \multicolumn{5}{c}{ Concentration (mM) } \\
\cline { 2 - 6 } & Antibiotics & 25 & 50 & 75 & 100 \\
\hline 1 & Tetracycline & +++ & ++++ & ++++ & ++++ \\
2 & Ampicillin & - & ++ & ++++ & ++++ \\
3 & Rifampicin & - & - & - & + \\
4 & Streptomycin & ++ & +++ & ++++ & +++ \\
5 & Nalidixic acid & ++ & +++ & +++ & +++ \\
\hline
\end{tabular}

-: Sensitive, + : Less resistance, ++: Moderate resistance, +++ : High resistance, ++++: Very high resistance 
Table 5. Heavy Metal Tolerance exhibited by Pseudomonas sp. VSMKU4036

\begin{tabular}{lllllll}
\hline Heavy Metals & \multicolumn{7}{c}{ Concentration (mM) } \\
\cline { 2 - 6 } & 1 & 2 & 4 & 6 & 8 & 10 \\
\hline Lead acetate & - & - & - & - & - & - \\
Cadmium sulphate & ++ & ++ & +++ & ++++ & ++++ & ++++ \\
Nickel chloride & ++ & ++ & +++ & ++++ & +++ & ++++ \\
Selenium dioxide & - & - & - & +++ & +++ & +++ \\
Zinc sulphate & ++ & +++ & +++ & +++ & +++ & ++++ \\
Ferric chloride & + & ++ & +++ & +++ & ++++ & ++++ \\
Copper sulphate & ++ & +++ & ++++ & ++++ & ++++ & ++++ \\
Mercuric chloride & - & - & - & - & - & - \\
Magnesium sulphate & ++ & +++ & ++++ & ++++ & ++++ & ++++ \\
\hline
\end{tabular}

-: Sensitive, + : Less resistance, ++ : Moderate resistance, +++ : High resistance , ++++: Very high resistance

that can cause severe diseases like nerve and neuron relates diseases such as diabetic's, cancer, paralysis, and eye blindness. Hence, biosorption, biodegradation, and biomineralization by the microorganisms is the only way for the alternative method to protect our ecosystem without any harmful effect.

\section{CONCLUSION}

Plant rhizospheric microorganism Pseudomonas sp. VSMKU4036 could be used as a microbial antagonist and can be used to remove pesticides, antibiotics deposits and deprivation of heavy metal from agricultural land. In addition, microorganisms of the rhizosphere may be developed as a current inoculant, a remarkable innovation and replacement for ecologically approachable plant disease control and increasing plant productivity.

\section{ACKNOWLEDGMENTS}

We would like to thank the Department of Microbial Technology and the Chairperson, School of Biological Sciences, Madurai Kamaraj University, Madurai, and The Head, Department of Botany, Vivekananda College, Thiruvedagam-west, Madurai, Tamil Nadu for providing laboratory and instrumentation facilities.

\section{CONFLICT OF INTEREST}

The authors declare that there is no conflict of interest.

\section{AUTHORS' CONTRIBUTIONS}

GV, carried out research and generate the data and drafted the manuscript. KN, PS, and MR worked for manuscript interpretation, NB, SG, and PTM outline and reviewed the manuscript and VS administered and revised the manuscript for improvisation. GS, PTM and VS read and approved the manuscript.

\section{FUNDING}

University Grants Commission, New Delhi, India (39-214/2010 (SR) dated: 27.12.2010).

\section{ETHICS STATEMENT}

Not applicable.

\section{DATA AVAILABILITY}

All data were generated or analyzed during this study and included in the manuscript.

\section{REFERENCES}

1. Ahemad M, Kibret M. Mechanisms and applications of plant growth promoting rhizobacteria: current perspective. J King Saud Univ Sci. 2014;26(1):1-20. https://doi.org/10.1016/j.jksus.2013.05.001

2. Ahmad F, Ahmad I, Aqil F, Ahmed Wani A, Sousche YS. Plant growth promoting potential of freeliving diazotrophs and other rhizobacteria isolated from Northern Indian soil. Biotechnology Journal: Healthcare Nutrition Technology. 2006;1(10): 112-123. https://doi.org/10.1002/biot.200600132

3. Alstrom S, Burns RG. Cyanide production by rhizobacteria as a possible mechanism of plant growth inhibition. Biology and Fertility of Soils. 1989;7(3):232238. https://doi.org/10.1007/BF00709654 
4.

Ansari MI, Grohmann E, Malik A. Conjugative plasmids in multi-resistant bacterial isolates from Indian soil. J Appl Microbiol. 2008;104(6):1774-81. https://doi. org/10.1111/j.1365-2672.2008.03736.x

5. Antoun $\mathrm{H}$, Kloepper JW. Plant growth promoting rhizobacteria. Encyclopedia of genetics. Eds. S Brenner and J Miller. 2001:1477-1480. https://doi. org/10.1006/rwgn.2001.1636

6. Aznar A, Dellagi A. New insights into the role of siderophores as triggers of plant immunity: what can we learn from animals?. J Exp Bot. 2015;66(11):30013010. https://doi.org/10.1093/jxb/erv155

7. Baishya K, Sarma HP. Effect of agrochemicals application on accumulation of heavy metals on soil of different land uses with respect to its nutrient status. IOSR J Environ Sci Toxicol Food Technol. 2014;8(7):4654. https://doi.org/10.9790/2402-08724654

8. Barbieri P, Galassi G, Galli E. Plasmid-encoded mercury resistance in a Pseudomonas stutzeri strain that degrades o-xylene. FEMS Microbiol Ecol. 1989;5(6):375383. https://doi.org/10.1111/j.1574-6968.1989. tb03393.x

9. Bauer AW, Kirby WM, Sherris JC. turck, Turck M. Antibiotic susceptibility testing by a standardized single disk method. Am J Clin Pathol. 1966;45(4):493. https:// doi.org/10.1093/ajcp/45.4_ts.493

10. Bharathi $R$, Vivekananthan $R$, Harish $S$, Ramanathan $A$, Samiyappan R. Rhizobacteria-based bio-formulations for the management of fruit rot infection in chillies. Crop Protection. 2004;23(9):835-843. https://doi. org/10.1016/j.cropro.2004.01.007

11. Buch JJ, Lalitha G, Pathak TK, et al. Structural and elastic properties of Ca-substituted LaMnO3 at $300 \mathrm{~K}$. Journal of Physics D: Applied Physics. 2008;41(2):025406. https://doi.org/10.1088/0022-3727/41/2/025406

12. Cernava $T$, Muller $H$, Aschenbrenner $\mid A$, Grube $M$, Berg G. Analyzing the antagonistic potential of the lichen microbiome against pathogens by bridging metagenomic with culture studies. Front Microbiol. 2015;6:620. https://doi.org/10.3389/ fmicb.2015.00620

13. Charulatha R, Harikrishnan H, Manoharan PT, Shanmugaiah V. Characterization of groundnut rhizosphere Pseudomonas sp. VSMKU 2013 for control of phytopathogens. In Microbiological Research In Agroecosystem Management. 2013 (pp. 121-127). Springer, India. https://doi.org/10.1007/978-81-3221087-0_8

14. Egamberdiyeva $D$. The effect of plant growth promoting bacteria on growth and nutrient uptake of maize in two different soils. Applied Soil Ecology. 2007;36(2-3):184189. https://doi.org/10.1016/j.apsoil.2007.02.005

15. Feng J, Shi Q, Wang X, Wei M, Yang F, Xu H. Silicon supplementation ameliorated the inhibition of photosynthesis and nitrate metabolism by cadmium (Cd) toxicity in Cucumis sativus L. Scientia Horticulture. 2010;123(4):521-530. https://doi.org/10.1016/j. scienta.2009.10.013

16. Glick BR, Penrose DM, Li J. A model for the lowering of plant ethylene concentrations by plant growthpromoting bacteria. Journal of Theoretical Biology. 1998;190(1):63-68. https://doi.org/10.1006/ jtbi.1997.0532

17. Glick BR, Todorovic B, Czarny J, Cheng Z, Duan J, McConkey B. Promotion of plant growth by bacterial ACC deaminase. CRC Crit Rev Plant Sci. 2007;26(5-6):227242. https://doi.org/10.1080/07352680701572966

18. Gyaneshwar P, Kumar GN, Parekh LJ, Poole PS. Role of soil microorganisms in improving $P$ nutrition of plants. Plant and Soil. 2002;245(1):83-93. https://doi. org/10.1023/A:1020663916259

19. Harikrishnan H, Shanmugaiah V, Nithya K, et al. Enhanced production of phenazine-like metabolite produced by Streptomyces aurantiogriseus VSMGT1014 against rice pathogen, Rhizoctonia solani. J Basic Microbiol. 2016;56(2):153-161. https://doi. org/10.1002/jobm.201500362

20. Huang SH, Bing PE, Yang ZH, Chai LY, Zhou LC. Chromium accumulation, microorganism population and enzyme activities in soils around chromium-containing slag heap of steel alloy factory. Transactions of Nonferrous Metals Society of China. 2009;19(1):241-248. https:// doi.org/10.1016/S1003-6326(08)60259-9

21. Kabata-Pendias A, Pendias H. Trace elements in soils and plants-CRC Press. 2001:403. Boca Raton. https:// doi.org/10.1201/9781420039900

22. King EO, Ward MK, Raney DE. Two simple media for the demonstration of pyocyanin and fluorescin. The Journal of Laboratory and Clinical Medicine. 1954;44(2):301-307.

23. Kloepper JW, Rodriguez-Kabana R, Zehnder AW, Murphy JF, Sikora E, Fernandez C. Plant root-bacterial interactions in biological control of soilborne diseases and potential extension to systemic and foliar diseases. Australian Plant Pathology. 1999;28(1):21-26. https:// doi.org/10.1071/AP99003

24. Lal S, Singh R, Kumar R. Heavy metal concentration and bacterial load on Spinach (Spinacia oleracea L.) phyllosphere under different regions in Lucknow, Uttar Pradesh. International Journal of Pharmacy \& Life Sciences. 2013;1:4(7).

25. Lata SA. Characterization of plant growth promoting rhizobacteria. Training manual on biofertilizer technology. (Ed. AK Saxena). 2003:24-25.

26. Levy SB. The challenge of antibiotic resistance. Scientific American. 1998;278(3):46-53. https://doi. org/10.1038/scientificamerican0398-46

27. Liu M, Huang B, Bi X, Ren Z, Shenga G, Fu, J. Heavy metals and organic compounds contamination in soil from an e-waste region in South China. Environtal Science: Processes\& Impacts. 2013;15: 919-929. https://doi.org/10.1039/c3em00043e

28. Lorck H. Production of hydrocyanic acid by bacteria. Physiologia Plantarum, 1948; 1(2): 142-6. https://doi. org/10.1111/j.1399-3054.1948.tb07118.x

29. Lu RK, Shi ZY, Xiong LM. Cadmium contents of rock phosphates and phosphate fertilizers of China and their effects on ecological environment. Acta Pedologica Sinica. 1992;29(2):150-156.

30. Malik A, Aleem A. Incidence of metal and antibiotic resistance in Pseudomonas spp. from the river water, agricultural soil irrigated with wastewater and groundwater. Environmental Monitoring and Assessment. 2011;178(1-4):293-308. https://doi. 
org/10.1007/s10661-010-1690-2

31. Malik A, Celik EK, Bohn C, Bockelmann U, Knobel K, Grohmann E. Detection of conjugative plasmids and antibiotic resistance genes in anthropogenic soils from Germany and India. FEMS Microbiol Lett. 2008;279(2):207-216. https://doi.org/10.1111/j.15746968.2007.01030.x

32. Malik A, Jaiswal R. Metal resistance in Pseudomonas strains isolated from soil treated with industrial wastewater. World I Microbiol Biotechnol. 2000;16(2):177-182. https://doi. org/10.1023/A:1008905902282

33. Mobin M, Khan NA. Photosynthetic activity, pigment composition and antioxidative response of two mustard (Brassica juncea) cultivars differing in photosynthetic capacity subjected to cadmium stress. Journal of Plant Physiology. 2007;164(5): 601-610. https://doi.org/10.1016/j.jplph.2006.03.003

34. Mohammed AF, Oloyede AR, Odeseye AO. Biological control of bacterial wilt of tomato caused by Ralstonia solanacearum using Pseudomonas species isolated from the rhizosphere of tomato plants. Archives of Phytopathology and Plant Protection. 2020;53(1-2):16. https://doi.org/10.1080/03235408.2020.1715756

35. Mohan AJ, Sekhar VC, Bhaskar T, Nampoothiri KM. Microbial assisted high impact 730 polystyrene (HIPS) degradation. Bioresource Technology. 2016;213:204207. https://doi.org/10.1016/j.biortech.2016.03.021

36. Nithya K, Shanmugaiah V, Balasubramanian N, Gomathinayagam S. Plant Defence Related Enzymes in Rice (Oryzae sativa L.,) Induced by Pseudomonas sp. VSMKU2. J Pure Appl Microbiol. 2019; 13(3): 13071315. https://doi.org/10.22207/JPAM.13.3.02

37. Palleroni NJ. Introduction to the family Pseudomonadaceae. In The prokaryotes Springer, Berlin, Heidelberg. 1981;655-665. https://doi. org/10.1007/978-3-662-13187-9_58

38. Pikovskaya RI. Mobilization of phosphorus in soil in connection with the vital activity of some microbial species. Microbiology. 1948;17:362-370.

39. Prigent-Combaret C, Zghidi-Abouzid O, Effantin G, Lejeune P, Reverchon S, Nasser W. The nucleoidassociated protein Fis directly modulates the synthesis of cellulose, an essential component of pelliclebiofilms in the phytopathogenic bacterium Dickeya dadantii. Molecular Microbiology. 2012;86(1):172-186. https://doi.org/10.1111/j.1365-2958.2012.08182.x

40. Riah W, Laval K, Laroche-Ajzenberg E, Mougins C, Latour X, Trinsoutrot-Gattin I. Effects of pesticides on soil enzymes: a review. Environmental Chemistry Letters. 2014;12(2):257-273. https://doi.org/10.1007/ s10311-014-0458-2

41. Saberi AR, Hassan SA. The effects of nitrogen fertilizer and plant density on mustard (Brassica juncea); an overview. Global Advanced Research Journal of Agriculture Science. 2014;3(8):205-210.

42. Schwyn B, Neilands JB. Universal chemical assay for the detection and determination of siderophores. Anal Biochem. 1987;160(1):47-56. https://doi. org/10.1016/0003-2697(87)90612-9

43. Shanmugaiah V, Mathivanan N, Balasubramanian N, Manoharan PT. Optimization of cultural conditions for production of chitinase by Bacillus laterosporous MML2270 isolated from rice rhizosphere soil. African Journal of Biotechnology. 2008;7(15).

44. Shanmugaiah V, Mathivanan N, Varghese B. Purification, crystal structure and antimicrobial activity of phenazine-1-carboxamide produced by a growth-promoting biocontrol bacterium, Pseudomonas aeruginosa MML2212. J Appl Microbiol. 2010;108(2):703-711. https://doi.org/10.1111/j.13652672.2009.04466.x

45. Shanmugaiah V, Nithya K, Harikrishnan $H$, Jayaprakashvel M, Balasubramanian N. Biocontrol mechanisms of siderophores against bacterial plant pathogens. Sustainable Approaches to Controlling Plant Pathogenic Bacteria. CRC Press, Taylor and Francis group, New York. 2015:167-190.

46. Shanmugaiah V, Ramesh S, Jayaprakashvel M, Mathivanan N. Biocontrol and plant growth promoting potential of Pseudomonas sp. MML2212 from the rice rhizosphere. Mitteilungen-Biologischen Bundesanstalt Fur Land Und Forstwirtschaft. 2006;408: 320.

47. Sharma SB, Sayyed RZ, Trivedi MH, Gobi TA. Phosphate solubilizing microbes: sustainable approach for managing phosphorus deficiency in agricultural soils. Springer Plus. 2013;2(1):587. https://doi. org/10.1186/2193-1801-2-587

48. Singh R, Arora NK, Gautam P, Lal S. Enhancement of plant growth of Trigonella foenum-graecum by Coinculation of fluorescent Pseudomonas and Rhizobium for the sustainability of agriculture. Asian Journal of Plant Science and Research. 2013;3(3):7479.

49. Timmusk S, Behers L, Muthoni J, Muraya A, Aronsson AC. Perspectives and challenges of microbial application for crop improvement. Frontiers in Plant Science, 2017;8:49. https://doi.org/10.3389/ fpls.2017.00049

50. Vacheron J, Desbrosses G, Bouffaud ML, et al. Plant growth-promoting rhizobacteria and root system functioning. Frontiers in Plant Science. 2013;4:356. https://doi.org/10.3389/fpls.2013.00356

51. Vaishnavi S, Thamaraiselvi C, Vasanthy M. Efficiency of Indigenous Microorganisms in Bioremediation of Tannery Effluent. In Waste Water Recycling and Management. Springer, Singapore. 2019;151-168. https://doi.org/10.1007/978-981-13-2619-6_13

52. Williams ST, Holt JG, Krieg NR, Sneath PH, Staley JT. Bergey's manual of determinative bacteriology: 1994. 9th. Baltimor, William \& Wilkins.

53. Yang C, Guo W, Li G, Gao F, Lin S, Zhang T. QTLs mapping for Verticillium wilt resistance at seedling and maturity stages in Gossypium barbadense L. Plant Science. 2008;174(3):290-298. https://doi.org/10.1016/j. plantsci.2007.11.016

54. Yang $\mathrm{W}, \mathrm{Xu} \mathrm{Q}$, Liu HX, et al. Evaluation of biological control agents against Ralstonia wilt on ginger. Biological Control. 2012;62(3):144-151. https://doi. org/10.1016/j.biocontrol.2012.05.001

55. Zhang N, Yang D, Wang D, et al. Whole transcriptomic analysis of the plant-beneficial rhizobacterium Bacillus amyloliquefaciens SQR9 during enhanced biofilm formation regulated by maize root exudates. $B M C$ 
Genomics. 2015;16(1):685. https://doi.org/10.1186/ s12864-015-1825-5

56. Zheng $\mathrm{Y}, \mathrm{Xue} \mathrm{QY}, \mathrm{Xu} \mathrm{LL}$, et al. A screening strategy of fungal biocontrol agents towards Verticillium wilt of cotton. Biological Control. 2011;56(3):209-216. https://doi.org/10.1016/j.biocontrol.2010.11.010

57. Zhou D, Huang XF, Chaparro JM, et al. Root and bacterial secretions regulate the interaction between plants and PGPR leading to distinct plant growth promotion effects. Plant and Soil. 2016;401(1-2): 259272. https://doi.org/10.1007/s11104-015-2743-7

58. Zhou T, Chen D, Li C, et al. Isolation and characterization of Pseudomonas brassicacearum J12 as an antagonist against Ralstonia solanacearum and identification of its antimicrobial components. Microbiological Research. 2012;167(7):388-394. https://doi.org/10.1016/j. micres.2012.01.003 